Published by LPMP Imperium

Journal homepage: https:/ / ejournal.imperiuminstitute.org/ index.php/ BERDAYA

\title{
Media Sosialisasi Penerimaan D alam Meningkatkan Recruitment Calon Mahasiswa Baru
}

\author{
Suryani \\ IAIN Lhokseumawe, A ceh
}

\begin{abstract}
The higher education admission selections are intended to obtain excellent prospective students. The opportunities are given to all students who graduated from senior high, vocational and Islamic senior high, and Islamic boarding schools (D ayah) throughout Lhokseumawe. These activities involved some lecturers and academicians from The State Islamic Institute (IA IN) Lhokseumawe located in Alu A wee, M uara Dua District, Lhokseumawe City. The methods used in the SPM B socialization process were discussion and feedback to create two-way interactions. This socialization was intended that the senior high, Islamic High and Islamic boarding school students now at the end of their study can smoothly participate in SPM B, to educate the students who will soon become the prospective students to easily make their registrations by fulfilling the required conditions and determine their majors when registering SPM B in accordance with their interests.
\end{abstract}

Keywords

Sosialization,D iscussion,

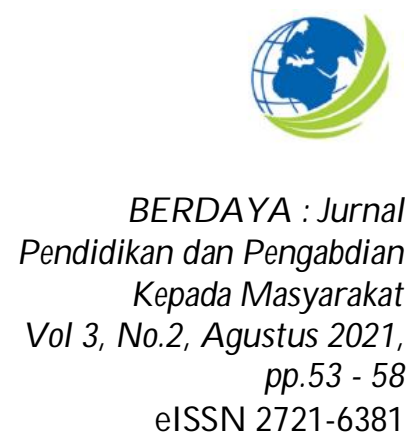

\section{Article History}

Received 03Aug 2020 / Accepted 1 De c2020 / First Published: 25Jul 2021

To cite this article

Suryani (2021). Media Sosialisasi Penerimaan Dalam Meningkatkan Recruitment Calon Mahasiswa Baru. BERDA Y A : Jurnal Pendidikan Dan Pengabdian Kepada M asyarakat, 3(2), 5358

DOI: $10.36407 /$ berdaya.v3i2.150

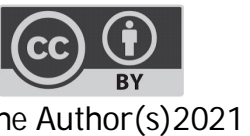

(C) The Author(s)2021

. This open access article is distributed under a Creative Commons

Attribution (CC-BY) 4.0 license 
ABSTRAK

Kegiatan seleksi masuk perguruan tinggi dimaksudkan untuk memperoleh calon mahasiswa yang unggul. Kesempatan untuk mengikuti seleksi diberikan kepada seluruh siswa/ siswi tamatan SMU/ SMK, dan MA dan Pesantren (Dayah) yang ada di sekitar kota Lhokseumawe. Kegiatan ini melibatkan beberapa dosen dan civitas akademis lainnya dari Institut Agama Islam Negeri (IAIN) Lhokseumawe yang berada di Alu Awee, Kecamatan Muara Dua, Kota Lhokseumawe. Metode yang digunakan dalam proses sosialisasi SPMB denganDiscussion and Feedback sehingga dalam proses sosialisasi terjadinya interaksi dua arah. Manfaat sosialisasi ini dimana peserta didik SMA, MA dan Pesantren yang sedang berada dibangku akhir dapat mengikuti SPMB dengan lancar, mengedukasi para pesertadidik yang akan menjadi calon mahasiswa agar mudah untuk melakukan pendaftaran dengan memenuhi syarat-syarat yang ditentukan, dapat menentukan jurusan apa yang akan mereka pilih ketika hendak mendaftar SPMB sesuai dengan minat para pesertadidik.

Korespondensi: Suryani email: suryapijar@yahoo.com

Kata Kunci : Sosialisasi, Diskusi, IA IN

Reviewing Editor

Hendryadi, STIE Indonesia

\section{PENDAHULUAN}

Mahasiswa merupakan suatu kelompok dalam masyarakat yang memperoleh status terkait dengan perguruan tinggi dengan batas usia sekitar 18-30 tahun. Menurut Winarno (2012) mahasiswa mempunyai peran sebagai agen perubahan sosial seperti yang tercantum dalam tridharma perguruan tinggi (pendidikan, peneliti, dan pengabdian masyarakat).

Berdasarkan Undang-Undang Nomor 12 Tahun 2012 tentang Pendidikan Tinggi dan Peraturan Pemerintah Republik Indonesia Nomor 4 Tahun 2014 tentang Penyelenggaraan Pendidikan Tingkat Tinggi dan Pengelolaan Perguruan Tinggi, ditetapkan bahwa pola penerimaan mahasiswa baru pada UIN/ IAIN/ STAIN disebut Seleksi Prestasi Akademik Nasional Perguruan Tinggi Keagamaan Islam Negeri (SPAN-PTKIN) dan pola pola seleksi dalam bentuk lain yang dilakukan secara bersama oleh UIN/IAIN/ STAIN disebut Ujian Masuk Perguruan Tinggi Keagamaan Islam Negeri (UM-PTKIN) yang kedua pola tersebut diikuti oleh calon mahasiswa dari seluruh Indonesia tanpa membedakan jenis kelamin, agama, ras, suku, kedudukan sosial, dan tingkat kemampuan ekonomi.

SPAN-PTKIN merupakan pola seleksi yang dilaksanakan secara nasional oleh seluruh UIN/ IAIN/ STAIN dalam satu sistem yang terpadu dan diselenggarakan secara serentak oleh Panitia Pelaksana yang ditetapkan oleh Menteri Agama Republik Indonesia. Biaya pelaksanaan SPAN-PTKIN ditanggung oleh pemerintah, sehingga peserta tidak dipungut biaya pendaftaran. Pelaksanaan SPAN-PTKIN secara nasional yang diikuti oleh seluruh PTKIN harus memenuhi prinsip adil, transparan, dan tidak diskriminatif dengan tetap memberikan potensi calon mahasiswa dan kekhususan PTKIN. PTKIN sebagai 
penyelenggara pendidikan setelah SMA/SMK/MA/MAK/ Pesantren Mu'adalah dapat menerima calon mahasiswa yang berprestasi akademik tinggi dan diprediksi akan berhasil menyelesaikan studi di PTKIN berdasarkan rekomendasi dari Kepala Sekolah/ Madrasah. Siswa yang berprestasi tinggi dan secara konsisten menunjukkan prestasinya tersebut layak mendapatkan kesempatan untuk menjadi calon mahasiswa di UIN/IAIN/ STAIN melalui SPAN-PTKIN.

Sosialisasi Seleksi Penerimaan Mahasiswa Baru (SPMB) kepada para cal on mahasiswa yang masih duduk di bangku Sekolah Menengah Atas (SMA) Sederajat, dilaksanakan dengan tujuan agar mereka paham sistematika dalam proses pendaftaran masuk ke Perguruan Tinggi Keagamaan Islam Negeri (PTKIN) Khususnya IAIN Lhokseumawe.

Seiring dengan kemajuan zaman dan perkembangan ilmu pengetahuan yang begitu pesat keberadaan mahasiswa baru sebagai generasi penerus bangsa menjadi asset berharga bagi keberadaan Institut Agama Islam Negeri (IAIN) Lhokseumawe dan pemerintah setempat dalam mencetak kader pengemban amanah kemajuan peradaban Islam.

IAIN Lhokseumawe saat ini membuka 4 (empat) fakultas yang terdiri dari Fakultas Tarbiyah dan IImu Keguruan (FTIK), Fakultas Syariah (FASYA), Fakultas Ushuludin Adab dan Dakwah (FUAD), dan Fakultas Ekonomi dan Bisnis Islam (FUAD). Seluruh progam studinya juga sudah mendapatkan peringkat akreditasi dari Badan A kreditasi Nasional Perguruan Tinggi (BAN-PT).Pola soialisasi ke sekolah-sekolah menengah atas, yang selama ini dilakukan adalah melakukan jalur sosialisasi konvensional dengan melakukan tatap muka (audiensi) dengan pihak sekolah dan siswa kelas tiga, lalu memberikan brosur/ leaflet dan atribut lainnya, metode lain dilakukan juga dengan broadcast di media sosial berupa Website, FB, WA, IG di surat kabar, kerjasama dengan berbagai pihak luar, melakukan kegiatan sosial kemasyarakatan dan lain sebagainya.

\section{Masalah yang ingin dipecahkan}

Berdasarkan hasil kunjungan Tim Sosialisasi pada beberapa Sekolah M enengah A tas (SMA), MA, Pesantren (Dayah) dan sederajat, maka berhasil diperoleh informasi terkait permasalahan yang dialami oleh siswa/siswi yang berkeinginan untuk melanjutkan studinya di perguruan tinggi, sebagai berikut:

1. Kurangnya informasi yang mumpuni mengenai seleksi masuk perguruan tinggi negeri.

2. Kurangnya tingkat kesadaranakan pendidikan karena terbentur oleh faktor ekonomi yang lemah.

3. Tidak menyadari akan potensi diri, sehingga tidak mampu menentukan jurusan apa yang harus dipilih.

4. Dominasi siswa perempuan dari pada laki-laki.

5. Kurangnya informasi terhadap beasiswa yang tersedia, sehingga para siswa merasa putus asa.

6. Jalur masuk perguruan tinggi negeri yang beragam, membuat mereka para siswa menjadi bingung diakibatkan oleh informasi yang mereka dapatkan kurang jelas.

7. Ketidakpahaman mereka terhadap alur dan sistemati ka pendaftaran kuliah. 


\section{MATERI DAN METODE}

\section{Metode Pel aksanaan}

Metode Pelaksanaan yang dipergunakan dalam rangka Sosialisasi SPAN-PTKIN adalah diskusi, penyuluhan, dan tanya jawab mengenai cara, proses, dan pengembangan potensi diri dari para peserta didik.

\section{Waktu Efektif Pelaksanaan}

Waktu pelaksanaan pelatihan dibutuhkan kurang dari satu bulan dimulai dari proses kunjungan kebeberapa rumah sekolah, dan pondok pesantren, analisis permasalahan yang terjadi pada para siswa/ siswi, diskusi bersama kepala sekolah, wakil kepala, dan pimpinan pondok pesantren, penyajian materi, serta tanya jawab bersama para siswa. Pelaksanaan Sosialisasi ini adalah bentuk kepedulian kampus dan instansi yang berkaitan kepada para calon mahasiswa yang masih minim pengetahuannya tentang tata cara pendaftaran kuliah. Kegiatan ini dilakukan untuk mengevaluasi apakah informasi yang beredar mengenai pendaftaran masuk perguruan tinggi sudah merata ke semua sekolah dan individu.

\section{Evaluasi Kegiatan}

Setelah proses pelaksanaan diadakan evaluasi untuk melihat apakah sosialisasi yang diberikan memiliki indikator kerberhasilan. Evaluasi yang dilakukan adalah dengan menerima feedback dari para siswa, dan dewan guru di SMA, MAS dan Pondok Pesantren tempat diadakannya sosialisasi.

\section{Indikator Keberhasilan}

Ukuran indikator kerberhasilan sosialisasi bisa dilihat dari antusiasme para siswa dan dewan guru serta pemimpin sekolah dalam mengikuti dan memberikan kesempatan dalam sosialisasi ini, dan juga feedback dari siswa/ i yang terlihat bersemangat memberikan beragam pertanyaan sekaligus mendengarkan informasi yang disampaikan. Ada dua indikator keberhasilan: (1) antusiasme siswa/ i ketika mengikuti kegiatan, dan (2) meningkatnya pengetahuan mereka tentang SPMB-PTKIN.

\section{Pelaksanaan Kegiatan}

\section{HASIL DAN PEMBAHASAN}

Pendidikan mempunyai peranan yang sangat sentral dan strategis, terutama jika dikaitkan dengan upaya peningkatan mutu sumber daya manusia (SDM), karena hanya dengan sumber daya manusia yang berkualitaslah akan tercipta peningkatan harkat dan martabat manusia yang sejati.

Perguruan Tinggi sebagai salah satu bagian penting dalam dunia pendidikan yang ikut bertanggungjawab dalam upaya mencerdaskan kehidupan bangsa mempunyai tanggungjawab dan peran yang sangat strategis untuk mengambil bagian dalam mengatasi permasalahan kualitas sumber daya manusia.

Penugasan kepada dosen sesuai dengan surat tugas tentang pelaksanaan kegiatan sosialisasi seleksi penerimaan mahasiswa baru (SPMB) pada tanggal 7 Februari 2020, maka kegiatan sosialisasipun mulai dilakukan sesuai dengan arahan dan instruksi dari bapak Wakil Rektor I IAIN Lhokseumawe, kegiatan dilaksanakan tanggal 10 Februari 2020 dimana tim sosialisasi 
berkunjung ke beberapa sekolah baik SMA, MAN, dan Pondok Pesantren (Dayah) untuk melakukan penyuluhan dan sosialisasi tersebut.
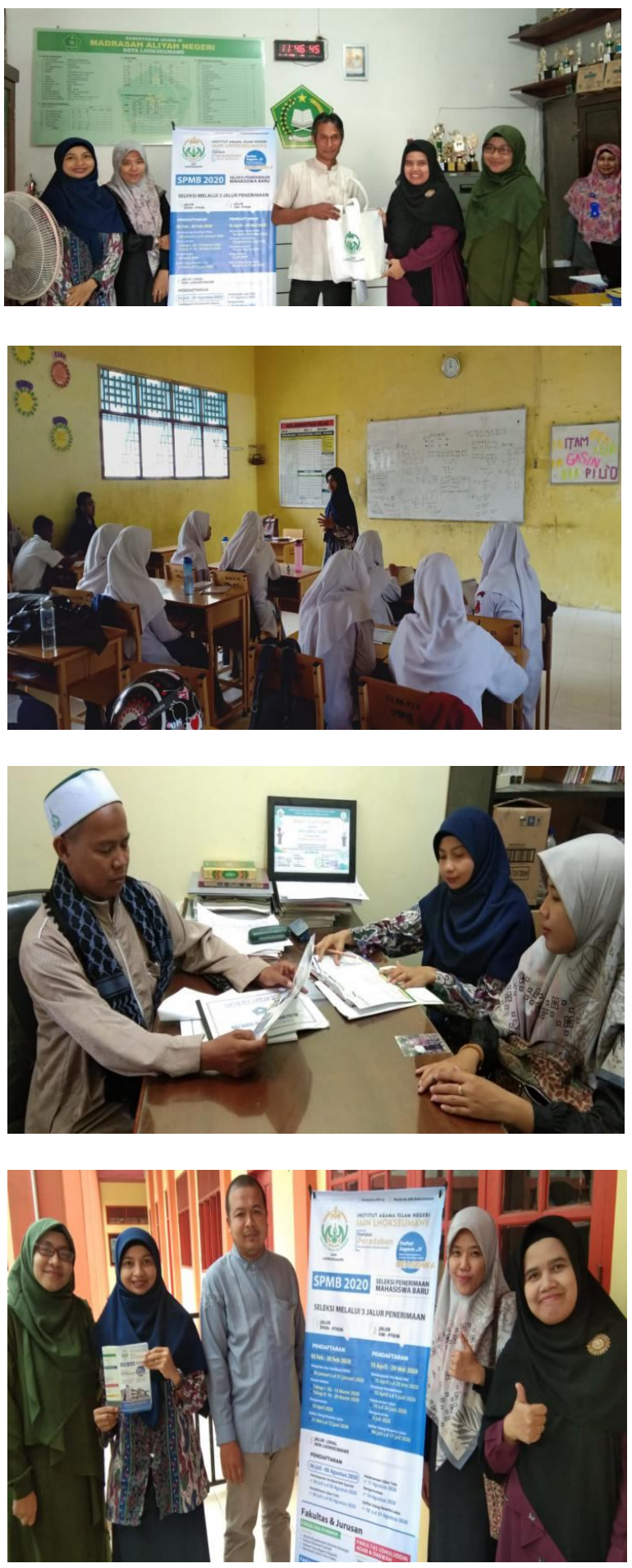

Gambar 1. Tim Sosialisasi mengunjungi Sekolah MAN 1 Kota Lhokseumawe

Sumber : Dokumentasi tim Pelaksana (2020)

Bu Suryani melakukan interaksi secara langsung sehingga memperlancar proses sosialisasi

Tim memberikan penjelasan terhadap pimpinan pondok pesantren

Foto bersama tim dan wakil kesiswaan SMA Negeri 2 Lhokseumawe

Dari kegiatan sosialisasi tersebut, ada beberapa harapan dari para pemipin sekolah yang berharap agar peserta didik mereka dapat diterima semua di jalur undangan pada seleksi 
penerimaan mahasiswa baru (SPMB) tahun 2020, dan hal ini juga bukan hanya sekedar harapan, namum dibuktikan pula dengan keadaan sekolah yang saat tim berkunjung sedang melakukan simulasi ujian nasional agar para siswa dapat lulus dengan nilai yang baik sehingga dapat diterima di perguruan tinggi negeri.

\section{KESIM PULAN}

Kegiatanpelaksanaan sosialisasi ini dimana para pemimpin sekolah SMA, MAN, dan Pondok Pesantren berperan sebagai penyedia lokasi sosialisasi. Siswa/ i dan santri bertindak sebagai peserta diskusi sosialisasi seleksi penerimaan mahasiswa baru (SPMB) PTKIN. Hasil dari kegiatan ini berupa terpenuhi segala keingintahuan para siswa/ i yang memiliki niat untuk melanjutkan pendidikannya di jenjang yang lebih tinggi, membuka mindset para santri yang masih ragu untuk mengejar cita-citanya karena terkendala oleh biaya, serta memberi harapan dan motivasi bagi semua peserta sosialisasi untuk tetap berani melangkah dan mengejar impian dengan melanjutkan pendidikan di perguruan tinggi.

\section{REFEREN SI}

Japarudin, Model Sosialisasi IAIN Bengkulu, Jurnal Manhaj, LPPM IAIN Bengkulu, https:/ / ejournal.iainbengkulu.ac.id/ index.php/ manhaj/ article/ view/ 147/ 135, diakses 15A pril 2020.

Rahmat, J. (2005). Psikologi Komunikasi. Bandung: Remaja Rosdakarya.

Rifa Nurafifah Syabaniah. 2017. Pengaruh Antara Media Sosial dan Sosialisasi Informasi Terhadap M inat Memilih Perguruan Tinggi. Jurnal SWABUMI, Vol. 5 N o.2 September 2017.

https:span-ptkin.ac.id/ page

\section{A bout Author}

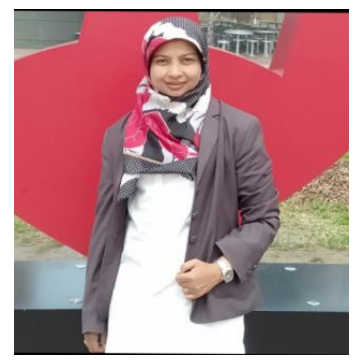

Suryaniadalah dosen PNS pada Fakultas Ekonomi dan Bisnis Islam, Institut Agama Islam Negeri Lhokseumawe, Aceh. Penulis dapat dihubungi di alamat email: suryapijar@yahoo.com

\section{Declarations}

\section{Funding}

Kegiatan ini merupakan bagian dari program Pengabdian Kepada Masyarakat yang didanai oleh Institut A gama Islam N egeri Lhokseumawe, Tahun 2020.

\section{Competing Interests}

Tidak ada konflik kepentingan untuk diungkapkan. 